\title{
Rapid progression of mitral and aortic stenosis in a patient with secondary hyperparathyroidism
}

\author{
Kenichi Fujise, Richard Amerling, Warren Sherman
}

\begin{abstract}
A 68 year old woman with chronic renal failure on long-term haemodialysis presented with progressive dyspnoea. Serial echocardiography showed a rapid reduction in mitral valve area from 2.18 to 0.92 $\mathrm{cm}^{2}$ over 18 months. In addition, the previously non-stenotic aortic valve was found to be severely stenotic with a valve area of $1.05 \mathrm{~cm}^{2}$. Cardiac catheterisation confirmed these findings. The patient had undergone subtotal parathyroidectomy more than 10 years before but had chemical and clinical evidence consistent with recurrent hyperparathyroidism. The patient underwent successful mitral and aortic valve replacement with relief of symptoms. Rapid progression of both aortic and mitral valve stenosis in the presence of secondary hyperparathyroidism is a rare finding.
\end{abstract}

(Br Heart f 1993;70:282-284)

Progression of aortic ${ }^{1-4}$ and mitral stenosis ${ }^{5}$ has been estimated at about 0.1 and $0.09 \mathrm{~cm}^{2}$ a year respectively. However, the wide variation in the rate of progression is unexplained.

We report a patient with secondary hyperparathyroidism in whom mild mitral stenosis progressed to a critical level and in whom a nearly normal aortic valve become severely stenotic over 18 months.

Though rapid progression of either aortic or mitral valve stenosis has been reported in the presence of secondary hyperparathyroidism ${ }^{6} 7$ rapid progression of both aortic and mitral valve stenosis has not.

\section{Case report}

A 68 year old white woman with a history of hypertension was well until 12 years before admission when haemodialysis was started for chronic renal failure. Three years later, the patient developed several pathological fractures. Secondary hyperparathyroidism was diagnosed and subtotal parathyroidectomy was performed. The patient did well thereafter until two years before admission when she noted dyspnoea on exertion. Eighteen months before admission, an echocardiogram showed mild mitral stenosis with a mitral valve area of $2 \cdot 18 \mathrm{~cm}^{2}$. The mitral annulus was moderately calcified. The aortic valve was thickened but opened normally. Left ventricular function was normal. There was no history of rheumatic fever or infective endocarditis. Despite medical treatment dyspnoea progressed over the next 18 months to New York Heart Association class III. The patient was admitted for the evaluation of the refractory dyspnoea.

On examination, a grade $3 / 6$ systolic ejection murmur was noted at the base with radiation to the heart apex and neck. A mild mid-diastolic murmur was heard. Repeat echocardiography now showed severe mitral stenosis and moderately severe aortic stenosis (fig 1). The mitral valve area was $0.92 \mathrm{~cm}^{2}$
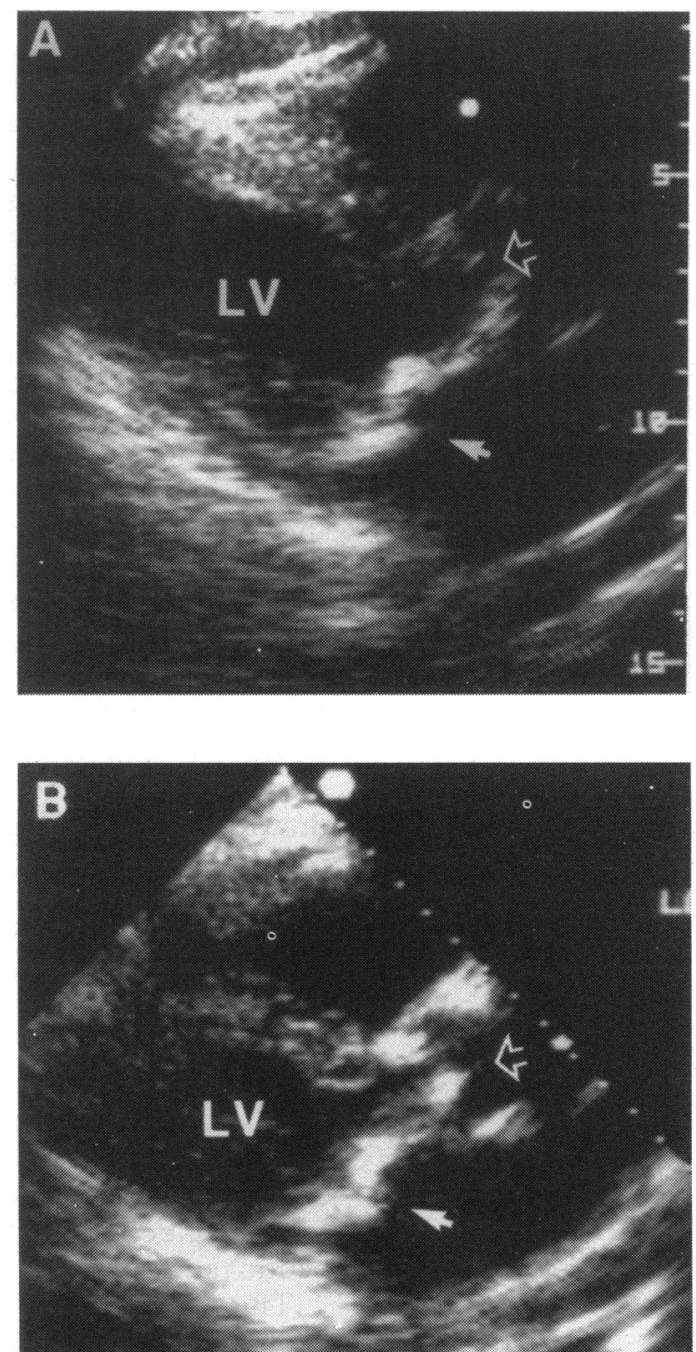

Figure 1 Echocardiographic evidence of progression of valvar stenoses (A) Cross sectional echocardiogram (May 1991) in a parasternal long axis view showing a slightly thickened aortic valve opening normally and moderate calcification of the mitral annulus. A Doppler study showed mild mitral stenosis pressure half time 101s, corresponding to a mitral valve area of $2 \cdot 18 \mathrm{~cm}^{2}$. (B) Repeat study 18 months later showing considerable calcification of the aortic and mitral valves and annuli. Pressure half time at this time was $239 \mathrm{~s}$, indicating a presence of critical mitral stenosis with mitral valve area of $0.92 \mathrm{~cm}^{2}$. In addition, Doppler study and a calculation based on a continuous equation indicated an aortic valve area of $1.05 \mathrm{~cm}^{2}$. Open arrow, aortic valve; solid arrow, mitral valve; $L V I$, left ventricle. 
Summary of laboratory findings at presentation.

\begin{tabular}{|c|c|c|}
\hline Tests & Values & Normal range \\
\hline Blood urea nitrogen $(\mathrm{mmol} / \mathrm{l})$ & $17 \cdot 9$ & $2 \cdot 9-7 \cdot 5$ \\
\hline Creatinine $(\mathrm{mmol} / \mathrm{l})$ & $751 \cdot 4$ & 53-106 \\
\hline Calcium $\left(^{\star}\right)(\mathrm{mmol} / \mathrm{l})$ & $2 \cdot 45$ & $2 \cdot 1-2 \cdot 6$ \\
\hline Phosphorus $\left({ }^{\star}\right)(\mathrm{mmol} / \mathrm{l})$ & $2 \cdot 36$ & $0.9-1 \cdot 3$ \\
\hline Product $\left(^{\star}\right)$. & $5 \cdot 78$ & $1 \cdot 9-3 \cdot 4$ \\
\hline Haemoglobin $(\mathrm{mmol} / \mathrm{l})$ & $5 \cdot 89$ & $7 \cdot 4-9 \cdot 9$ \\
\hline $\begin{array}{l}\text { N-terminal parathyroid hormone } \\
(\mu \mathrm{Eg} / \mathrm{ml})\end{array}$ & $20 \cdot 0$ & $0-6 \cdot 1$ \\
\hline $\begin{array}{l}\text { 1,25-dihydroxy Vitamin D (pmol/l) } \\
\text { 25-hydroxy Vitamin D }(\mathrm{nmol} / 1)\end{array}$ & $\begin{array}{l}67 \cdot 2 \\
44 \cdot 8\end{array}$ & $\begin{array}{l}36-144 \\
34 \cdot 9-105\end{array}$ \\
\hline
\end{tabular}

${ }^{\star}$ Mean of all the available preoperative values.

and the aortic valve area was $1.05 \mathrm{~cm}^{2}$. Blood chemistry (table) and bone studies (fig 2) suggested secondary hyperparathyroidism. A review of laboratory data from the previous nine years showed chronic hyperphosphataemia, with an average calcium-phosphorus product of 71 . Subsequent cardiac catheterisation through a transseptal approach confirmed the presence of critical mitral and aortic stenosis. Mitral regurgitation was mild. The coronary arteries showed mild obstructive disease. Heavy calcification of mitral annulus, aortic valve, and all coronary arteries was evident on fluoroscopic examination of the heart.

The patient underwent aortic and mitral valve replacement. Intraoperatively, the

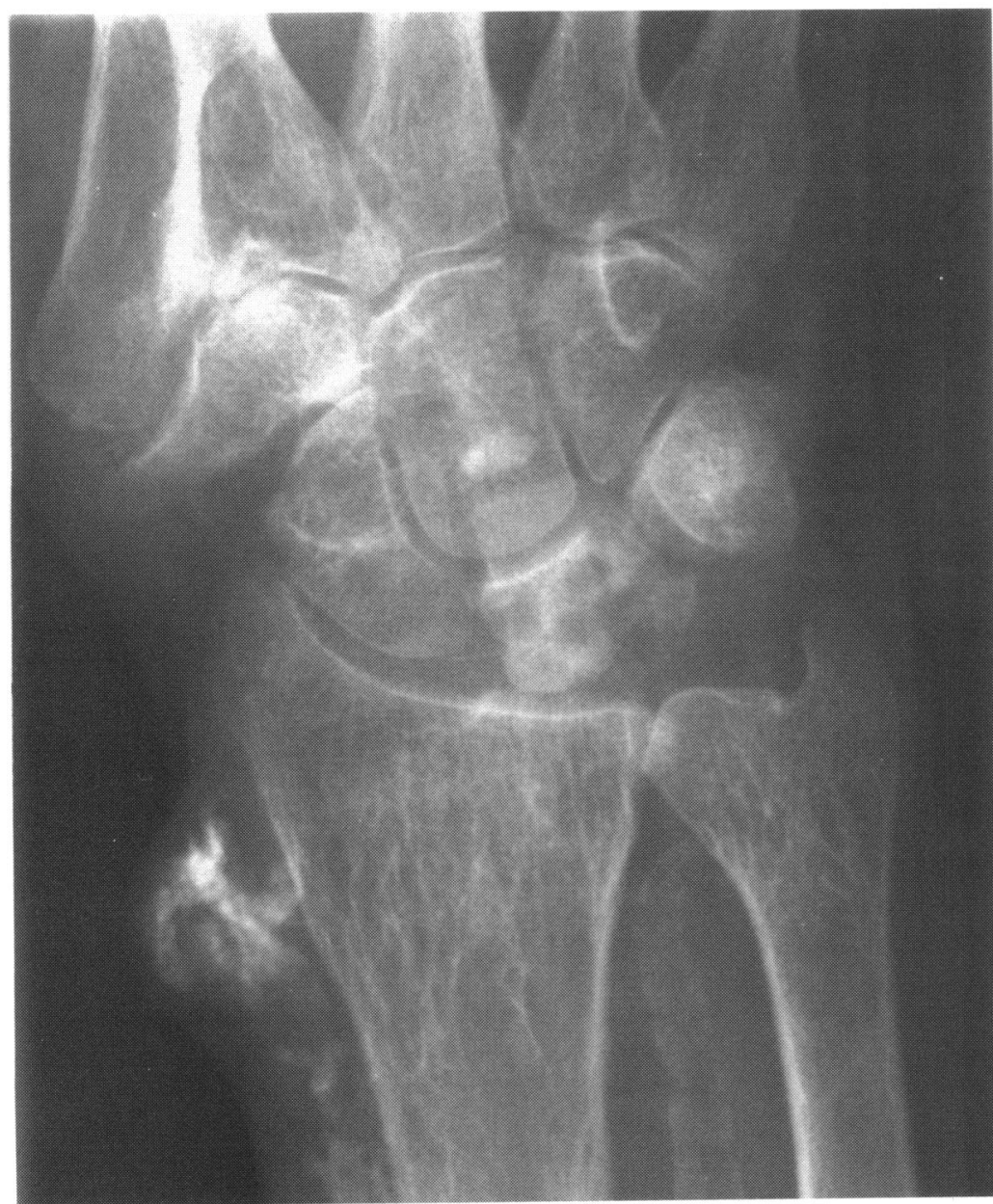

Figure 2 Bilateral hand $x$ ray examination at the time of presentation showed advanced bilateral osteoarthropathy with generalised osteopenia, resorption of distal tufts, erosive periarticular changes, and carpal bone cyst formation. There was also diffuse calcification of the radial and ulnar arteries as well as a large amorphous soft tissue calcification just medial to the distal radial artery, corresponding to an old fistula. These findings are medial to the distal radial are arathyroidism. The bone cysts are typical of dialysisassociated amyloidosis. mitral and aortic valves were found to be heavily calcified and severely stenotic. Pathological examination confirmed heavy calcification in both aortic and mitral valve structures. The postoperative course was uneventful. The patient was discharged two weeks later with considerable relief of symptoms.

\section{Discussion}

Progression of aortic stenosis has been studied by several groups using either cardiac catheterisation or echocardiography. The mean annual decrease in aortic valve area has been reported to be 0.05 to $0.1 \mathrm{~cm}^{2} .{ }^{1-4}$ The rate of progression varied widely, ranging from actual regression of stenosis to annual progression of over $0.7 \mathrm{~cm}^{2}$. A degenerative aortic valve, ${ }^{1}$ smaller initial aortic valve area, larger initial peak aortic valve gradient, ${ }^{2}$ and left ventricular dysfunction ${ }^{4}$ are risk factors for rapid progression.

Progression of mitral valve stenosis has been systematically evaluated only by Gordon et al. ${ }^{5}$ They followed up 50 patients with mild to severe rheumatic mitral stenosis with echocardiograms over 39 months and found a mean decline in valve area of $0.09 \mathrm{~cm}^{2} /$ year. Again the rate of progression was highly variable, ranging from actual regression to rapid progression of $1.0 \mathrm{~cm}^{2}$ annually. The group with rapid progression had a higher mean and peak transmitral gradients as well as increased valve thickening and calcification.

In our patient both mitral and aortic valve stenoses progressed rapidly. Serial echocardiography showed reductions in mitral and aortic valve area of $0.8 \mathrm{~cm}^{2} /$ year and 0.6 $\mathrm{cm}^{2} /$ year respectively.

In chronic renal failure a persistently raised calcium-phosphate double product, usually due to secondary hyperparathyroidism, can result in varying degrees of soft tissue calcification. Various cardiac structures can become calcified in this setting. ${ }^{69}$ Asymptomatic calcification of heart valves has been reported in up to a third of such patients, though haemodynamically significant calcific valve stenosis is infrequent, with a reported incidence of 1 and $3 \%$ for mitral and aortic valves, respectively. ${ }^{10}$

Though enhanced progression of valve stenoses in the presence of secondary hyperparathyroidism has never been proven systematically, case reports support the possibility. ${ }^{67}$ Depace et al reported the case of a 52 year old man with a previously normal mitral valve who over a 36 month period developed significant stenosis with the valve area of $2.0 \mathrm{~cm}^{2} .6 \mathrm{McF}$ alls et al reported a 34 year old woman with a previously normal aortic valve that became critically stenotic over 18 months with the valve area of $0.6 \mathrm{~cm}^{2}{ }^{7}$ Our patient is unusual in having rapid progression of both mitral and aortic stenoses. All the patients described above had a radiographic evidence of secondary hyperparathyroidism and high calcium-phosphate products in the setting of chronic renal failure. 
In conclusion, the rate of progression of valve stenoses is likely to be influenced and modified by both local tear and shear forces and the systemic humoral environment. In future studies of the progression of valve stenosis, the role of the humoral milieu should be taken into account. The presence of high calcium-phosphate product and secondary hyperparathyroidism in the setting of chronic renal failure can increase the rate of progression of both mitral and aortic valve stenoses. Patients with chronic renal failure and value stenoses may benefit from the tight control of the calcium-phosphate product and the close monitoring of parathyroid hormone concentrations. Our report suggests that secondary hyperparathyroidism can cause rapid progression of valve stenoses, which is related to enhanced tissue deposition of calcium. This leads to a speculation that not only local physical stress but also systemic humoral environment plays an important part in the genesis and evolution of valvar heart disease.
1 Wagner S, Selzer A. Patterns of progression of aortic stenosis: a longitudinal hemodynamic study. Circulation 1982;65:709-12.

2 Nestico PF, DePace NL, Kimbiris D, et al. Progression of isolated aortic stenosis: analysis of 29 patients having more than 1 cardiac catheterization. Am $\mathcal{\Im}$ Cardiol 1983; 52:1054-8.

3 52:1054-8.

Otto C, Pearlman AS, Gardner C. Hemodynamic progression of aortic stenosis in adults assessed by Doppler

4 Faggiano P, Ghizzoni G, Sorgato A, et al. Rate of progresFaggiano $\mathrm{P}$, Ghizzoni G, Sorgato A, et al. Rate of progres-
sion of valvular aortic stenosis in adults. Am $\mathcal{f}$ Cardiol 1992;70:229-33.

5 Gordon SPF, Douglas PS, Come PC, Manning WJ. Twodimensional and doppler echocardiographic determinants of the natural history of mitral valve narrowing in patients with rheumatic mitral stenosis: Implications for followup. F Am Coll Cardiol 1992;19:968-73.

6 Depace NL, Rorer AH, Kotler MN, et al. Rapidly progressing, massive mitral annular calcification. Arch Intern Med 1981;141:1663-5.

7 McFalls EO, Archer SL. Rapid progression of aortic stenosis and secondary hyperparathyroidism. Am Heart \begin{tabular}{l} 
Stenosis and secon \\
\hdashline $1990 ; 120: 206-8$.
\end{tabular}

8 D'Cruz IA, Fishman JM, et al. Calcification of the mitral region in patients with chronic renal failure: $2 \mathrm{D}$ echocardiographic, hormonal and autopsy correlation [abstr]. 7 Am Coll Cardiol 1983;1:625.

9 Forman MB, Virmani R, Robertson RM, Stone WJ. Mitral annular calcification in chronic renal failure. Chest 1984;85:367-71.

10 Maher ER, Yound G, Smyth-Walsh B, et al. Aortic and mitral valve calcification in patients with end-stage renal disease. Lancet 1987;ii:875-7. 